ARTICLE

DOI: $10.1038 / s 41467-017-02412-4$

OPEN

\title{
Impact on short-lived climate forcers increases projected warming due to deforestation
}

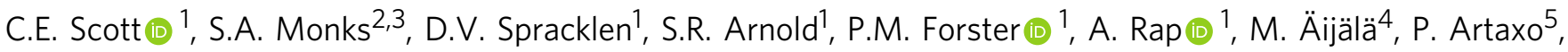

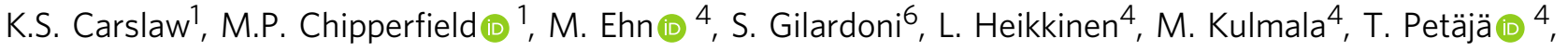 \\ C.L.S. Reddington ${ }^{1}$, L.V. Rizzo ${ }^{7}$, E. Swietlicki ${ }^{8,9}$, E. Vignatio ${ }^{10} \&$ C. Wilson ${ }^{1}$
}

The climate impact of deforestation depends on the relative strength of several biogeochemical and biogeophysical effects. In addition to affecting the exchange of carbon dioxide $\left(\mathrm{CO}_{2}\right)$ and moisture with the atmosphere and surface albedo, vegetation emits biogenic volatile organic compounds (BVOCs) that alter the formation of short-lived climate forcers (SLCFs), which include aerosol, ozone and methane. Here we show that a scenario of complete global deforestation results in a net positive radiative forcing ( $R F ; 0.12 \mathrm{~W} \mathrm{~m}^{-2}$ ) from SLCFs, with the negative RF from decreases in ozone and methane concentrations partially offsetting the positive aerosol RF. Combining RFs due to $\mathrm{CO}_{2}$, surface albedo and SLCFs suggests that global deforestation could cause $0.8 \mathrm{~K}$ warming after 100 years, with SLCFs contributing $8 \%$ of the effect. However, deforestation as projected by the RCP 8.5 scenario leads to zero net RF from SLCF, primarily due to nonlinearities in the aerosol indirect effect.

\footnotetext{
${ }^{1}$ Institute for Climate and Atmospheric Science, School of Earth and Environment, University of Leeds, Leeds, UK. ${ }^{2}$ Cooperative Institute for Research in Environmental Sciences, University of Colorado, Boulder, CO, USA. ${ }^{3}$ Chemical Sciences Division, NOAA Earth System Research Laboratory, Boulder, CO, USA. ${ }^{4}$ Department of Physics, University of Helsinki, P.O. Box 64, 00014 Helsinki, Finland. ${ }^{5}$ Institute of Physics, University of Sao Paulo, Diadema, Sao Paulo, Brazil. ${ }^{6}$ National Research Council, Institute of Atmospheric Sciences and Climate, Bologna, Italy. ${ }^{7}$ Department of Earth and Exact Sciences, Institute of Environmental, Chemical and Pharmaceutics Sciences, Federal University of Sao Paulo, UNIFESP, Diadema, Sao Paulo, Brazil. ${ }^{8}$ Division of Nuclear Physics, Lund University, P.O. Box 118, 22100 Lund, Sweden. ${ }^{9}$ Centre for Environmental and Climate Research, Lund University, P.O. Box 118, 22100 Lund, Sweden. ${ }^{10}$ European Commission, Joint Research Center, Directorate for Energy Transport and Climate, Ispra, Italy. Correspondence and requests for materials should be addressed to C.E.S. (email: c.e.scott@leeds.ac.uk)
} 
F orests cover almost one third of the Earth's land area and their distribution is changing as a result of land-use change (LUC). Since the Industrial Revolution the increased demand for agricultural land has resulted in the conversion of forests to crops and pastures over large parts of the world ${ }^{1}$. Rapid deforestation continues today with mean annual global forest loss of 0.19 million $\mathrm{km}^{2}$ between 2000 and 2012 driven by continued and intensifying deforestation in the tropics ${ }^{2}$. In the Amazon, $20 \%$ of the original forest has now been cleared ${ }^{3}$ and in Borneo forest cover declined by $31 \%$ between 1973 and $2010^{4}$. In other parts of the world, natural forest regrowth due to agricultural abandonment, as well as afforestation, has led to substantial regional increases in forest cover ${ }^{2}$. Future land cover trajectories may exacerbate or help to mitigate climate change. A recent assessment suggests that avoided deforestation, forest restoration and other land management options, could provide $37 \%$ of the cost effective carbon dioxide $\left(\mathrm{CO}_{2}\right)$ mitigation needed before 2030 to limit future warming to $2 \mathrm{~K}$ above pre-industrial levels ${ }^{5}$. The formulation of sound climate mitigation policy ${ }^{6}$ for the next century requires a robust understanding of the climate impacts associated with the current wide range of future LUC projections ${ }^{7}$.

Numerous biogeophysical and biogeochemical interactions between vegetation and the atmosphere ${ }^{8-11}$ complicate the climate impacts of LUC. Deforestation often results in the direct emission of $\mathrm{CO}_{2}$ through forest burning or decay of wood. This emission acts to increase the concentration of $\mathrm{CO}_{2}$ in the atmosphere ${ }^{12}$, resulting in a positive radiative effect, or warming, on climate. Forests are darker in colour than grass or cropland so deforestation increases the reflectivity of the land surface (i.e., its albedo). An increase in surface albedo will exert a negative radiative effect, or cooling, on the climate ${ }^{8}$. The net impact of these biogeochemical and biogeophysical effects depends strongly upon forest latitude: tropical deforestation is generally found to warm the climate whereas high latitude deforestation is generally found to cool the climate $\mathrm{c}^{8-10,13}$.

In addition to these effects, forests and vegetation emit biogenic volatile organic compounds (BVOCs) into the atmosphere. Rates of BVOC emission will be affected by LUC; this can affect climate by changing the concentrations of short-lived climate forcers (SLCFs) including aerosols, ozone $\left(\mathrm{O}_{3}\right)$ and methane $\left(\mathrm{CH}_{4}\right)$. Once emitted, BVOCs are rapidly oxidised by $\mathrm{O}_{3}$, the hydroxyl radical $(\mathrm{OH})$ and the nitrate radical $\left(\mathrm{NO}_{3}\right)$, affecting the oxidative capacity of the atmosphere. Any change to the oxidative capacity of the troposphere will affect the concentration of two important greenhouse gases, $\mathrm{O}_{3}$ and $\mathrm{CH}_{4}$. In the presence of nitrogen oxides $\left(\mathrm{NO}_{\mathrm{x}}\right)$, VOCs also contribute to $\mathrm{O}_{3}$ production in the troposphere, complicating their impact on climate ${ }^{14}$.

Low-volatility products from BVOC oxidation can participate in new particle formation ${ }^{15,16}$ as well as condensing onto existing particles in the atmosphere and aiding their growth to larger sizes ${ }^{17,18}$. Through these processes, secondary organic aerosol (SOA) formed by VOC oxidation, influences the number of climatically relevant particles in the atmosphere. Once particles have grown to a dry diameter of approximately $100 \mathrm{~nm}$ they can interact directly with incoming shortwave radiation (exerting a direct radiative forcing or effect) and act as condensation nuclei for the formation of cloud droplets (resulting in an indirect radiative forcing or effect). Through these direct and indirect radiative effects, the presence of biogenic SOA likely exerts a negative radiative effect on the climate ${ }^{19,20}$.

Most assessments of the climate impacts of LUC have been restricted to $\mathrm{CO}_{2}$ and biophysical impacts ${ }^{8-10,13}$. Only recently ${ }^{21-}$ 24 , have assessments of the overall climate impact of LUC considered the impacts on SLCFs. A study ${ }^{22}$ of the impacts of historical LUC on SLCFs, suggested that reductions in BVOCs due to LUC have reduced $\mathrm{O}_{3}$ and $\mathrm{CH}_{4}$ concentrations resulting in a climate cooling; however, this study did not fully evaluate aerosol radiative effects. Whilst other studies have assessed the impacts of complex historical ${ }^{22-25}$ or future LUC $^{24,26}$, our approach is to conduct idealised deforestation scenarios, allowing us to isolate the impact of this specific LUC on climate. Our focus is on the impact of deforestation on SLCFs via changes in BVOC emissions, so we do not include trace gas emissions associated with the agricultural activities that may occur on deforested land.

To further explore the implications of LUC on the production of SLCFs, we conducted idealised experiments of global, boreal $\left(90-50^{\circ} \mathrm{N}\right)$, temperate $\left(50-20^{\circ} \mathrm{N}\right.$ and $\left.20-50^{\circ} \mathrm{S}\right)$ and tropical $\left(20^{\circ}\right.$ $\mathrm{N}-20^{\circ} \mathrm{S}$ ) deforestation, consistent with previous studies of the $\mathrm{CO}_{2}$ and biogeophysical impacts of $\mathrm{LUC}^{9}$. To estimate the radiative impacts of deforestation we combine a land-surface model with a chemical transport model, global aerosol model, and radiative transfer model (see Methods). We also consider a level of future deforestation consistent with the RCP8.5 scenario. We focus on changes to forest cover in the present-day and future, since this is most relevant for climate change mitigation ${ }^{5}$.

We quantify the radiative forcing (RF) due to deforestation through changes in the concentration of SLCFs and compare these to the $\mathrm{CO}_{2}$ and biogeophysical impacts that are more routinely calculated. It is found that SLCFs contribute a net positive RF and enhance the warming associated with idealised large-scale deforestation.

\section{Results}

Evaluation against atmospheric observations. We evaluated simulated aerosol at boreal and tropical forest locations which are strongly influenced by the emission of BVOCs and less strongly perturbed by anthropogenic pollution ${ }^{27}$ (Supplementary Discussion). In boreal forest regions, the model underestimates both the number of cloud droplet forming particles and aerosol mass concentrations, with a contrasting overestimate of both parameters in tropical forest regions (Supplementary Fig. 1). To explore this issue we conducted an additional simulation where we increased the production of SOA from BVOCs by a factor of 5 in boreal latitudes and decreased the production of SOA by a factor of 2 at tropical latitudes, resulting in better agreement with observations at both locations. Applying these modified SOA yields reduces the simulated global SOA burden from $40 \mathrm{Tg}$

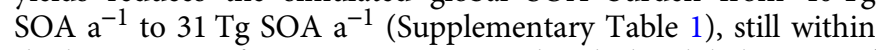
the large range of uncertainty associated with the global source of biogenic SOA ${ }^{28}$. Uncertainty in aerosol formation from BVOCs typically contributes less than $10 \%$ of total uncertainty in the simulated number of cloud droplet forming particles in our model $^{29}$, making it difficult to attribute model bias specifically to issues associated with SOA formation. However, we find limited sensitivity of aerosol RF to changes in SOA burden particularly for the aerosol indirect effect (Supplementary Table 2); we therefore report results from our deforestation experiments with standard SOA yields.

Simulated impacts of deforestation. Simulated global deforestation reduces isoprene emission by $87 \%$ and monoterpene emission by $94 \%$ (Supplementary Table 1), with the remaining emission coming from shrubs, crops and the grasses that replaced the forests. Most of this reduction in emission is due to tropical deforestation, which reduces isoprene and monoterpene emissions by 72 and $74 \%$ respectively. The reduction in BVOC emission due to simulated global deforestation reduces SOA production by $91 \%$ (Supplementary Table 1), with tropical deforestation accounting for $80 \%$ of the global reduction in SOA formation. 

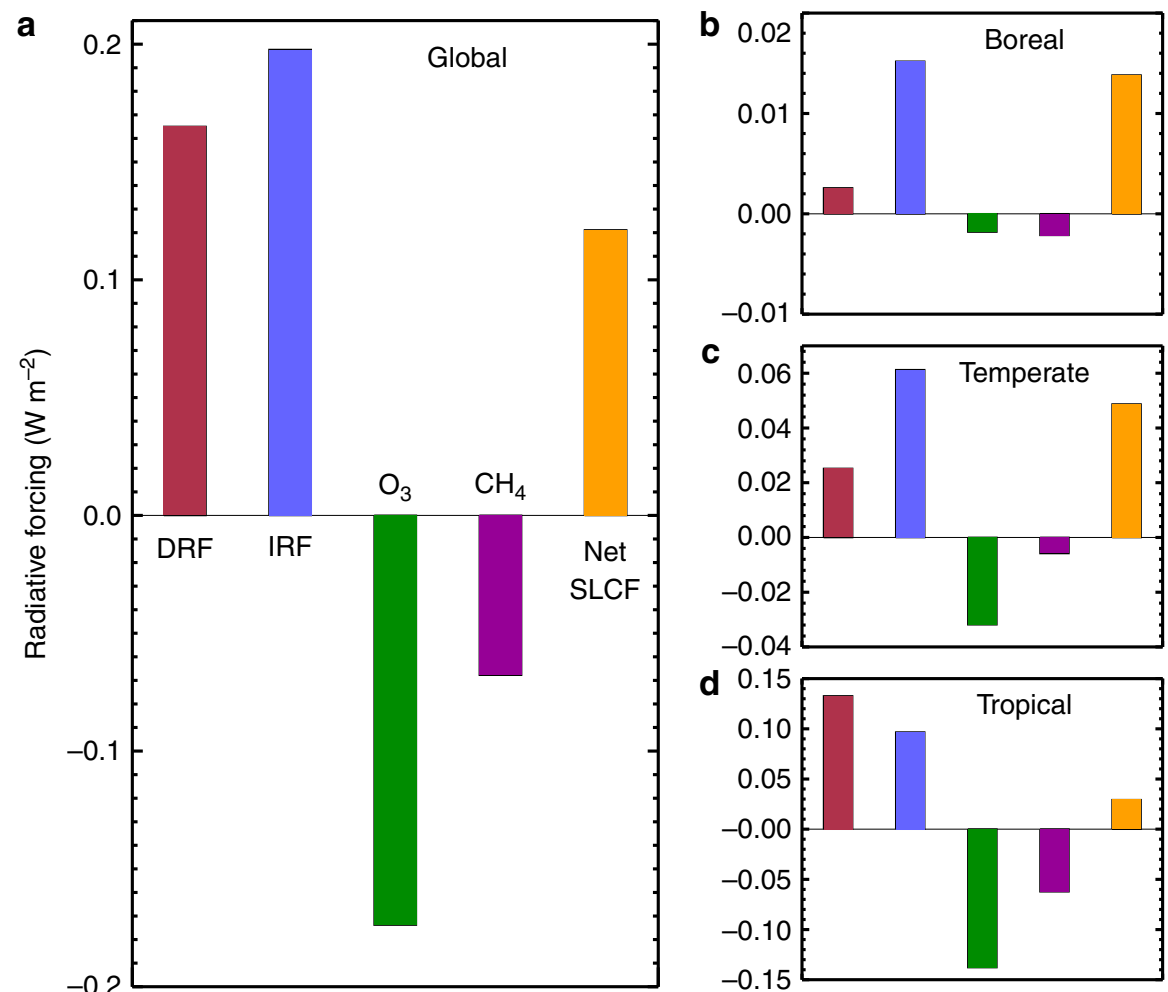

Fig. 1 Global annual mean radiative forcings due to changes in the concentrations of short-lived climate forcers (SLCFs) under global (a) and regional (b-d) deforestation scenarios. Bars represent the net radiative forcing from SLCFs (orange) and the aerosol direct radiative forcing (DRF; in red), first aerosol indirect radiative forcing (IRF; in blue) and $\mathrm{RF}$ due to changes in $\mathrm{O}_{3}$ (green) and $\mathrm{CH}_{4}$ (purple)
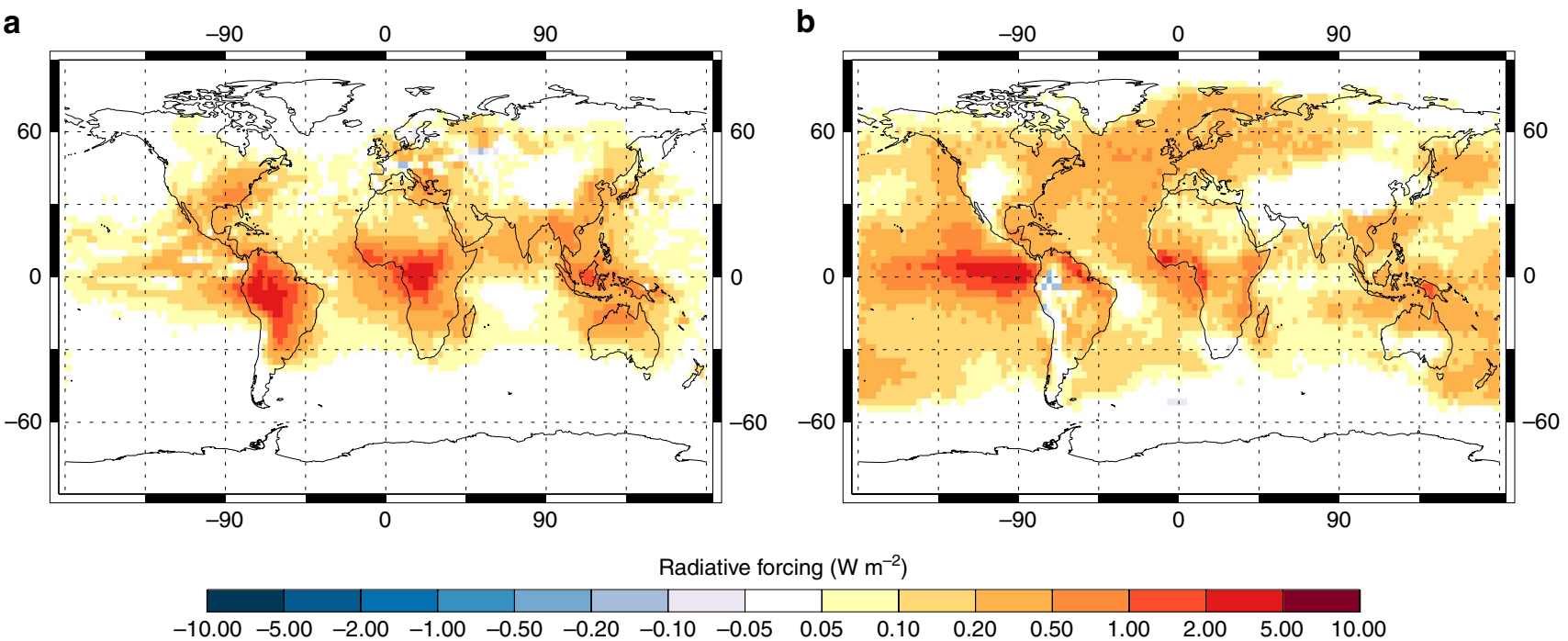

Fig. 2 Aerosol radiative effects due to global deforestation. Direct radiative forcing (a) and first indirect radiative forcing (b)

Figure 1 summarises the annual mean RFs due to changes in the concentrations of SLCFs under global and regional deforestation scenarios. Global deforestation results in a positive global annual mean aerosol direct radiative forcing (DRF) of $0.17 \mathrm{~W} \mathrm{~m}^{-2}$ (all values also given in Supplementary Table 2). This positive RF occurs due to the reduced production of biogenic SOA, meaning that fewer particles grow large enough to interact directly with radiation in the atmosphere. The largest DRF occurs over tropical regions, exceeding $2 \mathrm{~W} \mathrm{~m}^{-2}$ over the Amazon and Congo forests
(Fig. 2 and Supplementary Fig. 2). The different scenarios highlight a latitudinal sensitivity to deforestation, with tropical deforestation accounting for $80 \%$ of the DRF due to global deforestation.

Global deforestation causes a global annual mean first aerosol indirect radiative forcing (IRF) of $0.20 \mathrm{~W} \mathrm{~m}^{-2}$, due to a reduction in the global annual mean concentration of particles able to form cloud droplets. The spatial pattern of the IRF is more complex than the DRF (Fig. 2) but the strongest IRF also occurs at tropical 
a

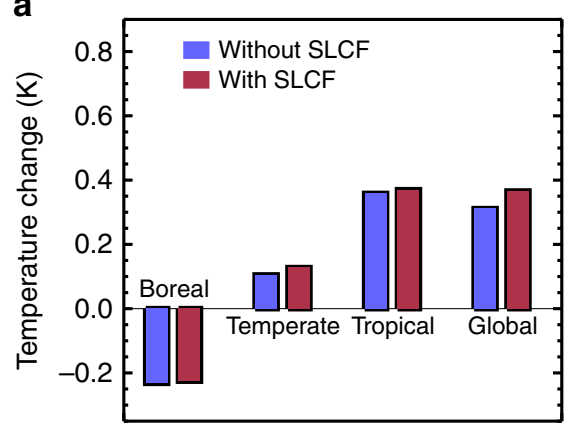

b

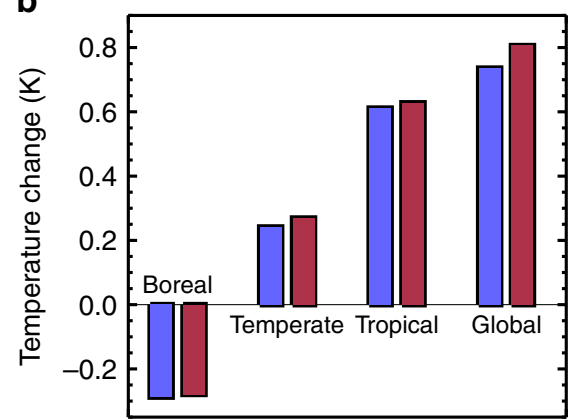

Fig. 3 Temperature changes due to deforestation. Net temperature changes after 20 years (a) and 100 years (b) for the global and regional deforestation scenarios, with and without the impacts of SLCFs

latitudes due to substantial year-round decreases in cloud droplet forming particles (up to 50\%) and the abundance of low-level clouds over the tropical coasts and adjacent ocean regions.

The strongest first IRF per change in SOA produced $(10 \mathrm{~mW} \mathrm{~m}$ $\left.-2 \mathrm{Tg}(\mathrm{SOA})^{-1}\right)$ comes from temperate $\left(20-50^{\circ} \mathrm{N}\right.$ and $\left.20-50^{\circ} \mathrm{S}\right)$ deforestation, which reduces global SOA production by only $15 \%$, but leads to a strong positive RF over remote ocean regions with high cloud cover. Boreal deforestation reduces the global annual mean concentration of particles able to form cloud droplets by only $1.4 \%$, but regional reductions over northern Russia and Canada in the NH summertime exceed $30 \%$. The combined contribution of temperate and boreal deforestation leads to a Northern hemisphere summertime (June-July-August mean) first IRF of more than $0.3 \mathrm{~W} \mathrm{~m}^{-2}$ across much of the region between 40 and $80^{\circ} \mathrm{N}$ (Supplementary Fig. 3).

In the present-day atmosphere, $\mathrm{NO}_{\mathrm{x}}$ concentrations are sufficiently high in most locations that BVOCs, particularly isoprene, contribute to the production of $\mathrm{O}_{3}$. As such, the reduction in BVOC emissions associated with global deforestation leads to a decrease in surface $\mathrm{O}_{3}$ concentration across much of the planet (Supplementary Fig. 4). However, in more pristine locations, such as over the Amazon rainforest, modelled $\mathrm{NO}_{\mathrm{x}}$ concentrations are low and direct reaction of BVOCs with $\mathrm{O}_{3}$ out-competes $\mathrm{O}_{3}$ production from BVOC oxidation. In these locations, the reduction in BVOC emission associated with deforestation leads to an increase in annual mean $\mathrm{O}_{3}$ concentrations at the surface (up to 11 ppbv; Supplementary Fig. 4). These increases diminish with altitude and the zonal mean change in $\mathrm{O}_{3}$ throughout the troposphere is negative at all latitudes (Supplementary Fig. 5).

Global deforestation leads to a global annual mean tropospheric $\mathrm{O}_{3}$ radiative forcing of $-0.17 \mathrm{~W} \mathrm{~m}{ }^{-2}$. The strongest $\mathrm{O}_{3} \mathrm{RF}$ is simulated for tropical deforestation $\left(-0.14 \mathrm{~W} \mathrm{~m}^{-2}\right)$. This is due to the relatively large perturbation to global BVOC emissions in a region where efficient convective transport of air masses from the surface to the upper troposphere enhances the impact of changes to $\mathrm{O}_{3}$ precursors, and because subsequent changes in $\mathrm{O}_{3}$ occur in the radiatively important tropical tropopause region ${ }^{30}$. Our simulated $\mathrm{O}_{3}$ RF due to global deforestation, is lower in magnitude than previous estimates ${ }^{31}$ of the radiative effect due to BVOC emission in the present day $\left(0.5 \mathrm{~W} \mathrm{~m}^{-2}\right)$; this could arise from differing model sensitivities to perturbations in $\mathrm{O}_{3}$ precursors, or the radiative effect per $\mathrm{O}_{3}$ change.

The reduction in BVOC emission associated with global deforestation leads to an increase in annual tropospheric mean $\mathrm{OH}$ concentration, from $1.36 \times 10^{6}$ to $1.46 \times 10^{6}$ molecules $\mathrm{cm}^{-3}$, which reduces the lifetime of $\mathrm{CH}_{4}$ from 7.6 years to 7.1 years. This change in $\mathrm{CH}_{4}$ lifetime is used to diagnose a reduction in steady-state $\mathrm{CH}_{4}$ concentration of $180 \mathrm{ppb}$ due to global deforestation, and a $\mathrm{RF}$ of $-0.07 \mathrm{~W} \mathrm{~m}^{-2}$. However, it is important to note that uncertainties in the consumption of $\mathrm{OH}$ during isoprene oxidation ${ }^{32,33}$ will influence the sensitivity of $\mathrm{CH}_{4}$ to changing BVOC emissions.

We calculate the combined impact of deforestation on the concentration of SLCFs through the combination of aerosol (DRF and first IRF), $\mathrm{O}_{3}$ and $\mathrm{CH}_{4}$ RFs. The combined RF from SLCFs is a balance between a warming aerosol RF and a cooling due to reductions in $\mathrm{O}_{3}$ and $\mathrm{CH}_{4}$. We estimate that global deforestation causes an overall positive RF of $0.12 \mathrm{~W} \mathrm{~m}^{-2}$ due to changes in SLCFs (Fig. 1). Our study demonstrates the importance of accounting for aerosol-cloud effects; when we ignore the first IRF, our combined SLCF RF is negative $\left(-0.08 \mathrm{~W} \mathrm{~m}^{-2}\right)$. Previous studies of the impact of deforestation or LUC on SLCFs that did not include the first IRF (e.g. ref. ${ }^{22}$, may therefore have attributed too much of a negative RF, or cooling effect, to changes in SLCFs from deforestation.

Figure 1 also shows the global RF due to regional deforestation simulations. The combined global mean SLCF RF due to tropical $\left(0.03 \mathrm{~W} \mathrm{~m}^{-2}\right)$, temperate $\left(0.05 \mathrm{~W} \mathrm{~m}^{-2}\right)$ and boreal $\left(0.01 \mathrm{~W} \mathrm{~m}^{-2}\right)$ deforestation are positive, due to the strong positive aerosol RFs in comparison to weaker negative $\mathrm{O}_{3}$ and $\mathrm{CH}_{4}$ RFs. Previous work, that accounted only for biogeophysical changes, has shown that the impact of temperate deforestation is seasonally dependent, causing a local summertime warming and a wintertime cooling ${ }^{13,34}$. Our analysis suggests that the effect of SLCFs would enhance this summertime warming. The impact of these temporally and spatially inhomogeneous RFs on regional climate may be important and needs to be explored in future work.

We also assessed the impact of deforestation that is consistent with the RCP8.5 scenario. Under this scenario the combined global mean SLCF RF is $0.00 \mathrm{~W} \mathrm{~m}^{-2}$ due to a warming aerosol RF being offset by cooling from changes in $\mathrm{O}_{3}$ and $\mathrm{CH}_{4}$. The DRF, $\mathrm{O}_{3}$ and $\mathrm{CH}_{4} \mathrm{RF}$ have a relatively linear response to changes in SOA, with SOA reductions of $4 \%$ in the RCP8.5 scenario vs $91 \%$ under global deforestation. In contrast, the IRF efficiency is reduced from $+5.4 \mathrm{~mW} \mathrm{~m}^{-2} \mathrm{Tg}(\mathrm{SOA})^{-1}$ under global deforestation to $-0.5 \mathrm{~mW} \mathrm{~m}^{-2} \mathrm{Tg}(\mathrm{SOA})^{-1}$ under the RCP8.5 scenario. This further highlights the non-linear responses between changes in SOA and IRF that were calculated in the regional deforestation experiments.

We calculate the natural variability of SLCF RF using an 11year GLOMAP simulation for the period 1997 to 2007. We calculate the standard deviation in the annual mean RE as 0.025 $\mathrm{W} \mathrm{m}{ }^{-2}$ for $\mathrm{DRF}$ and $0.017 \mathrm{~W} \mathrm{~m}^{-2}$ for IRF. This means that radiative impacts from global and regional deforestation (Supplementary Table 2) typically exceed natural variability, whereas the impact from the RCP8.5 scenario is substantially less than natural variability. 
Table 1 Summary of global annual mean radiative forcings due to idealised deforestation scenarios

\begin{tabular}{|c|c|c|c|c|}
\hline & 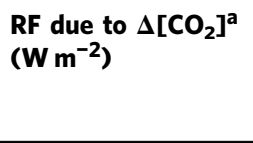 & $\begin{array}{l}\text { RF due to } \Delta \text { albedo } \\
\left(\mathbf{W ~ m}^{-2}\right)\end{array}$ & $\begin{array}{l}\text { RF due to } \Delta \text { SLCFs } \\
\left(W^{-2}\right)\end{array}$ & $\begin{array}{l}\text { Combined RF due to } \\
\mathrm{CO}_{2} \text { (after } 100 \text { years), } \\
\text { albedo and SLCFs } \\
\left(\mathrm{W} \mathrm{m}^{-2}\right)\end{array}$ \\
\hline $\begin{array}{l}\text { Temperate } \\
\text { deforestation }\end{array}$ & 0.71 & -0.27 & 0.05 & 0.49 \\
\hline $\begin{array}{l}\text { Tropical } \\
\text { deforestation }\end{array}$ & 1.26 & -0.18 & 0.03 & 1.11 \\
\hline $\begin{array}{l}\text { RCP8.5 level } \\
\text { deforestation in } \\
2100\end{array}$ & $0.24^{b}$ & $0.02^{b}$ & 0.00 & 0.26 \\
\hline
\end{tabular}

To assess the relative importance of the calculated RFs of changes to SLCFs from LUC they need to be compared to the RFs due to surface albedo change and $\mathrm{CO}_{2}$ emission (Supplementary Fig. 6; $\mathrm{CO}_{2}$ concentration values taken from ref. ${ }^{9}$ ), summarised in Table 1. We assume permanent land-use changes such that the RFs associated with changes to SLCFs and surface albedo are constant with time (i.e., from a change occurring in year 1 and persisting). The $\mathrm{CO}_{2}$ concentration, and associated RF, evolves over time as the carbon pools change (see Methods). We note that taking the $\mathrm{CO}_{2}$ concentration pathways from ref. ${ }^{9}$ may introduce slight differences in the distribution of plant functional types across the land-surface, from that used to calculate the SLCF and albedo RFs.

The global mean RF due to surface albedo change $\left(-0.96 \mathrm{~W} \mathrm{~m}^{-2}\right)$ under global deforestation is dominated by the impact of boreal deforestation, which alone exerts a global annual mean RF of $-0.51 \mathrm{~W} \mathrm{~m}^{-2}$. Consistent with previous studies ${ }^{8,24}$, the increase in surface albedo, and enhanced snow cover, due to boreal deforestation leads to strong regional RFs, up to $-25 \mathrm{~W} \mathrm{~m}^{-2}$ (not shown). Despite the large area affected, tropical deforestation results in a much smaller albedo change and a global annual mean $\mathrm{RF}$ of $-0.18 \mathrm{~W} \mathrm{~m}^{-2}$.

Simulated global deforestation in 2000 leads to a rapid increase in $\mathrm{CO}_{2} \mathrm{RF}$ that peaks in 2080 and gradually declines afterwards (Supplementary Fig. 7) ${ }^{9}$. The global mean atmospheric $\mathrm{CO}_{2}$ concentration remains approximately $380 \mathrm{ppm}$ above the baseline after 100 years, giving a $\mathrm{RF}$ of $2.22 \mathrm{~W} \mathrm{~m}^{-2}$ (Table 1). The $\mathrm{CO}_{2}$ changes come nearly entirely from deforestation at tropical and temperate latitudes; note that the carbon cycle model response is not completely linear so global deforestation has a larger effect than the sum of the regional components.

We estimate a combined RF due to global deforestation of 1.38 $\mathrm{W} \mathrm{m} \mathrm{m}^{-2}$ (100 years after deforestation, Table 1); including SLCFs increases the positive RF by $10 \%$. This enhancement from SLCFs is less than a previous study that also included $\mathrm{CH}_{4}$ and $\mathrm{N}_{2} \mathrm{O}$ emissions from agricultural activities after the initial $\mathrm{LUC}^{24}$. Boreal deforestation has a negative combined RF due to strong surface albedo effects, whereas temperate and tropical deforestation have a positive combined RF.

Temperature change due to deforestation. Standard metrics used to compare RFs are Global Warming Potentials (GWP) based on time integrated RFs, or Global Temperature Potential (GTP) based on end point global surface temperature change estimates $^{35}$. Here we chose to compare GTP after 20 and 100 years, assuming a mid-range equilibrium climate sensitivity. Our calculation of GTP ignores regional climatic implications, which may be particularly important for $\mathrm{LUC}^{36}$ and SLCFs where RFs are spatially inhomogeneous. The use of a single climate sensitivity to translate radiative forcing into global temperature change ignores the possibility that spatially variable forcings might have a different response to that of carbon dioxide and does not account for differences in the rapid adjustments across mechanisms ${ }^{37}$. Figure 3 shows the net impact of global, boreal, temperate and tropical deforestation, highlighting the contribution of SLCFs. Global deforestation leads to $0.36 \mathrm{~K}$ global surface warming after 20 years and $0.8 \mathrm{~K}$ warming after 100 years, when the effects of SLCFs are included.

For the case of global deforestation, including SLCFs increases the warming impact of deforestation (compared to that from $\mathrm{CO}_{2}$ and surface albedo alone) by around $0.05 \mathrm{~K}$, providing $14 \%$ of the total warming after 20 years, and $8 \%$ of the total warming after 100 years. As found previously ${ }^{8-10}$, boreal deforestation exerts a global net cooling (approximately $0.3 \mathrm{~K}$ after 100 years) due primarily to the dominant effect of increased surface albedo. Including the impacts in SLCFs reduces the magnitude of this net negative RF (from changes to $\mathrm{CO}_{2}$ and surface albedo alone) by approximately $3 \%$. We find that tropical deforestation results in a strong net global mean warming effect, consistent with previous studies ${ }^{9}$; including the impacts of SLCFs has a small effect on top of this.

\section{Discussion}

Our analysis confirms the need to differentiate between tropical and boreal LUC when considering climate impacts; even though our scenarios remove forests completely, they are suggestive that future deforestation outside of high latitudes is likely to result in a warming.

Extensive land-use change will dramatically alter fire activity with associated changes in emissions of trace gases and aerosol and climate 22,26 . Here we assumed that fire emissions continue following the initial deforestation, but future work needs to explore a representation of the complex relationships between deforestation and fire.

Further work is required to fully constrain the impacts of BVOCs on SLCFs. BVOC emission fluxes ${ }^{38}$ are uncertain, particularly in the tropics and for reactive BVOCs such as sesquiterpenes $^{39}$. The tropospheric oxidation of BVOCs ${ }^{32,33}$ and their role in SOA formation ${ }^{40}$ requires further elucidation, particularly in low $\mathrm{NO}_{\mathrm{x}}$ environments. Uncertainties also remain in our 
understanding of new particle formation mechanisms ${ }^{16}$, the interaction of biogenic oxidation products with other atmospheric constituents ${ }^{41}$ and aerosol microphysical processes ${ }^{18}$. Our understanding of the impacts of deforestation on $\mathrm{CO}_{2}$ concentrations and surface albedo are also subject to uncertainty, with estimates of the climate impact from both effects varying by up to a factor of two ${ }^{24,35}$. Future work is needed to quantitatively evaluate the uncertainty across the full range of biogeochemical and biophysical effects. Nevertheless, our study suggests that tropical deforestation would still warm the climate even if we assume a much larger role for SLCFs, such as the strongly negative $\mathrm{O}_{3} \mathrm{RF}$ that was calculated in another study ${ }^{22}$.

Land-use change has substantial impacts on climate through biogeophysical and biogeochemical effects. By combining the RFs due to $\mathrm{CO}_{2}$, surface albedo and SLCFs we find that global deforestation could lead to around $0.8 \mathrm{~K}$ warming after 100 years, assuming a mid-range climate sensitivity. Tropical deforestation contributes $0.6 \mathrm{~K}$ of the warming, whereas boreal deforestation cools the climate by around $0.3 \mathrm{~K}$ in our simple scenarios. Policies aimed at reducing tropical deforestation ${ }^{42}$ are therefore likely to reduce future climate warming. Whilst we have isolated the different impact of boreal, temperate and tropical deforestation on climate, policy discussions may need additional information on the sensitivity of the RF and climate impact to the specific location of deforestation. Land-use change may lead to important regional temperature changes ${ }^{43}$. Future work needs to move beyond the radiative forcing and global mean temperature changes reported here. We estimate that including the impacts of deforestation on SLCFs increases the warming from global deforestation by around $0.05 \mathrm{~K}$ (comprising $14 \%$ of the total warming after 20 years, $8 \%$ after 100 years).

\section{Methods}

Experimental design. To assess the magnitude of the radiative impacts associated with deforestation, we combine a land surface model, used to estimate the impact of deforestation on BVOC emissions, with a global chemical transport model and detailed aerosol microphysics model to calculate the impacts of altered BVOC emissions on the composition of the atmosphere. We then use a radiative transfer model to calculate the radiative impacts of changes to gas-phase and aerosol species, as well as alterations to surface albedo. We carry out idealised simulations of global and regional deforestation to match previous studies, estimating the $\mathrm{CO}_{2}$ and biophysical impacts of $\mathrm{LUC}^{9}$. In regional deforestation simulations, we separately remove boreal $\left(90-50^{\circ} \mathrm{N}\right)$, temperate $\left(50-20^{\circ} \mathrm{N}\right.$ and $\left.20^{\circ} \mathrm{S}-50^{\circ} \mathrm{N}\right)$, and tropical $\left(20^{\circ} \mathrm{N}-20^{\circ} \mathrm{S}\right)$ forests. Additionally, we evaluate the impact on SLCFs, through changes in BVOC emissions, of a level of deforestation consistent with the RCP8.5 scenario.

Land surface model. To quantify the effect of removing forests on the emission of BVOCs, we use the Community Land Model (CLMv4.0; ref. ${ }^{44)}$, which contains the Model of Emissions of Gases and Aerosols from Nature (MEGANv2.1; ref. ${ }^{38)}$.

Here we use the offline configuration of the CLM at a horizontal resolution of $2.5^{\circ} \times 1.9^{\circ}$. Precipitation, temperature, solar radiation, wind, atmospheric pressure and specific humidity fields are taken from an observationally derived data set based on NCEP/NCAR re-analysis ${ }^{45}$. All simulations are performed for the year 2000; since the simulations were run without an interactive carbon-nitrogen cycle, a 40 year spin-up period was sufficient to allow the soil moisture of the CLM to establish equilibrium with the driving meteorology.

Vegetation in the CLM is represented by 15 different plant functional types (PFTs), with additional non-vegetated surface in each grid cell. The distribution of PFTs in the CLM is based on MODIS data ${ }^{46,47}$. We simulate a global total monoterpene emission of $140 \mathrm{Tg}(\mathrm{C}) \mathrm{a}^{-1}$ and an isoprene emission of $480 \mathrm{Tg}(\mathrm{C}) \mathrm{a}^{-1}$ in our control simulation, consistent with previous emission estimates ${ }^{38}$. In the deforestation scenarios, forested regions of the land-surface were replaced with climatically appropriate grasses. To avoid scaling up potentially inaccurate leaf area indices (LAI) derived from satellite observations of a small initial area of PFT, the LAI for the grass PFTs (used to replace trees) were updated with the relevant latitudinal averages from the CLM land surface data set.

To evaluate the potential impact of future deforestation, we use the level of deforestation occurring between 2005 and 2100 , under the RCP8.5 scenario ${ }^{48}$, to scale our present-day BVOC emissions in proportion to the level of forest loss occurring by 2100 . This approach isolates the impact of land-use change from other factors that would affect BVOC emissions in 2100, such as changes in temperature and carbon dioxide concentration. To remain consistent with our complete deforestation scenarios, deforested regions in 2100 are effectively replaced by grass in our RCP 8.5 scenario.

Chemical transport model and aerosol microphysics model. We use the TOMCAT chemical transport model ${ }^{49}$ and the GLObal Model of Aerosol Processes (GLOMAP) ${ }^{50}$ to simulate the abundances of gas-phase and aerosol species. Both models operate at a horizontal resolution of $2.8 \times 2.8^{\circ}$, with 31 pressure levels from the surface to $10 \mathrm{hPa}$. European Centre for Medium-Range Weather Forecasts (ECMWF; ERA-Interim) reanalyses data drives the meteorology in both models at 6-hourly intervals. Cloud fields for the year 2000 are taken from the International Satellite Cloud Climatology Project (ISCCP) archive ${ }^{51}$. With both models, simulations are performed for the year 2000 (with 1 year spin-up) and emissions of BVOCs are taken from the CLM.

We use GLOMAP-mode to simulate changes to the size and number of climatically relevant particles in the atmosphere when the source of biogenic SOA is altered ${ }^{20}$. GLOMAP-mode is a two-moment model, carrying particle number and composition details in five log-normal size modes: hydrophilic nucleation, Aitken, accumulation and coarse modes, and a non-hydrophilic Aitken mode. GLOMAP includes representations of particle formation and growth (via coagulation, condensation and cloud processing), as well as removal via wet and dry deposition. Particle phase material is classified as either sea-salt, sulphate, black carbon (BC) or particulate organic matter (POM; containing both primary and secondary organic species). Anthropogenic emissions (BC, POM and sulphur dioxide; $\mathrm{SO}_{2}$ ) for the year 2000 from fossil and biofuel combustion are taken from refs. ${ }^{52,53}$. Biomass burning emissions $\left(\mathrm{BC}, \mathrm{POM}\right.$ and $\mathrm{SO}_{2}$ ) are from the Global Fire Emissions Database (GFEDv3; ref. ${ }^{54)}$ inventory for the year 2000 Marine emissions of dimethyl-sulphide (DMS) are calculated using DMS sea surface concentrations ${ }^{55}$ along with a sea-to-air transfer velocity ${ }^{56} . \mathrm{SO}_{2}$ emissions from both continuous ${ }^{57}$ and explosive ${ }^{58}$ volcanic eruptions are included.

Gas-phase BVOCs (monoterpenes and isoprene) are oxidised by $\mathrm{O}_{3}, \mathrm{OH}$ and $\mathrm{NO}_{3}$ to generate secondary organic products. These reactions proceed with rate constants and molar yields ( $13 \%$ for monoterpenes and $3 \%$ for isoprene) from ref. ${ }^{20}$. The secondary organic products generated are assumed to be nonvolatile and condense irreversibly onto existing particles in proportion to their Fuchs-Sutugin-corrected surface area ${ }^{59}$.

The new particle formation rate at $1.5 \mathrm{~nm}\left(J^{*}\right)$ is parameterised according to ref. ${ }^{15}$ (Eq. 1) with $k=5 \times 10^{-13} \mathrm{~s}^{-1}$; here NucOrg is the nucleating organic species. Subsequent growth of newly formed particles up to $3 \mathrm{~nm}$ is parameterised according to ref. ${ }^{60}$.

$$
J_{\mathrm{ORG}}^{*}=k\left[\mathrm{H}_{2} \mathrm{SO}_{4}\right][\mathrm{NucOrg}]
$$

In the standard configuration of GLOMAP-mode ${ }^{50}$, one gas-phase tracer is used to represent the oxidation products of monoterpenes and isoprene $e^{20}$. For this work, an additional gas-phase tracer is added to track the products of monoterpene and isoprene oxidation independently. The product of monoterpene oxidation contributes to both new particle formation (as NucOrg) and condensational growth, while the product of isoprene oxidation contributes only to condensational growth.

GLOMAP takes offline oxidants from equivalent deforestation simulations performed with the TOMCAT chemical transport model. This ensures that the gasphase oxidant concentrations are consistent with the deforestation scenario. Monthly-mean oxidant concentrations $\left(\mathrm{O}_{3}, \mathrm{OH}, \mathrm{NO}_{3}, \mathrm{HO}_{2}\right.$ and $\left.\mathrm{H}_{2} \mathrm{O}_{2}\right)$ are read in at 6-h intervals; this simplification means that simulated changes to aerosol processes, due to deforestation, will not alter tropospheric chemistry. $\mathrm{O}_{3}, \mathrm{OH}$ and $\mathrm{NO}_{3}$ take part in the oxidation of BVOCs and formation of secondary organic aerosol. $\mathrm{HO}_{2}$ and $\mathrm{H}_{2} \mathrm{O}_{2}$ control the in-cloud oxidation of $\mathrm{SO}_{2}$, as described in ref. ${ }^{50} ; \mathrm{H}_{2} \mathrm{O}_{2}$ is treated semi-prognostically and is replenished by $\mathrm{HO}_{2}$ selfreaction.

To simulate the impact of deforestation on gas-phase tropospheric chemistry, we use the TOMCAT chemical transport model ${ }^{61}$. TOMCAT includes the ExTC extended VOC degradation chemistry, simulating the oxidation of several $\mathrm{C}_{2}$ to $\mathrm{C}_{7}$ hydrocarbons. Monoterpene oxidation is based on the MOZART-3 scheme ${ }^{62,63}$ while the Mainz Isoprene Mechanism ${ }^{64}$ is applied to isoprene oxidation. Gas-phase emissions for the year 2000 are taken from the IPCC Fifth Assessment Report (AR5) anthropogenic inventory ${ }^{65}$ and the GFEDv3.1 inventory ${ }^{54}$. In addition to the BVOCs emitted by vegetation (calculated offline using the CLM), soil and marine emissions are included from the POET inventory ${ }^{66}$. A diurnal cycle is imposed on isoprene emissions within the model to reflect their dependence on daylight. Lightning emissions of $\mathrm{NO}_{\mathrm{x}}$ are coupled to convection and calculated online. Methane $\left(\mathrm{CH}_{4}\right)$ emission sources include EDGARv3.2 anthropogenic ${ }^{67}$, wetland and rice ${ }^{68}$, GFEDv3.1 fire ${ }^{54}$, and other natural emissions (treated as in ref. ${ }^{69}$ ). $\mathrm{CH}_{4}$ is emitted into the boundary layer of the model and at each time step surface concentrations are scaled to match a global mean concentration of $1800 \mathrm{ppbv}$; this approach generates a realistic spatial distribution, consistent with high and low emission regions. An offline aerosol size distribution from the GLOMAP model ${ }^{50}$ is used to calculate loss of $\mathrm{N}_{2} \mathrm{O}_{5}$ by aerosol uptake; this does not vary between our different deforestation scenarios.

Dry deposition of both gas- and particle-phase species is affected by characteristics of the land-surface. To simulate deforestation in GLOMAP, the 
characteristic radius and roughness length applied to the deforested land area were adjusted from forested values $(0.1-2 \mathrm{~m}$ and $5 \mathrm{~mm}$ respectively) to appropriate values for grass $\left(0.1 \mathrm{~m}\right.$ and $2 \mathrm{~mm}$ respectively), following ref. ${ }^{70}$. In TOMCAT, the land type classification map is altered under the deforestation scenarios by converting the forest cover type to the crop/shrub/grass cover type, giving a less efficient dry deposition velocity for species including $\mathrm{O}_{3}$.

We use an 11-year GLOMAP simulation for the period 1997-2007 to provide information on the interannual variability in aerosol radiative effects. This simulation includes variability in both natural and anthropogenic aerosol emissions.

Comparison to observations. In the boreal region, we compare GLOMAP output to monthly mean size distribution data collected (from 1996 to 2011) using a differential mobility particle sizer ${ }^{71}$, and composition data collected using an aerosol chemical speciation monitor ${ }^{72}$ (from 2012 to 2014) at Hyytiälä, Finland $\left(61.9^{\circ} \mathrm{N}, 24.3^{\circ} \mathrm{E}\right)^{73}$. Particle size distributions are used to calculate the number concentration of particles with dry diameter greater than $80 \mathrm{~nm}\left(\mathrm{~N}_{80}\right)$.

In the tropics, we compare GLOMAP to measurements made at the TT34 tower, $60 \mathrm{~km}$ north-northwest of Manaus $\left(2.60^{\circ} \mathrm{S}, 60.21^{\circ} \mathrm{W}\right)$. Monthly mean size distribution data collected during 2008-2009 using a scanning mobility particle sizer (SMPS) ${ }^{74,75}$ was used to derive $\mathrm{N}_{80}$ concentrations; we include only SMPS data that could be validated (and agreed to within 15\%) by comparison to particle number concentrations measured with a condensation particle counter. We also compare GLOMAP to composition data collected at the same site during 2008 as part of the European Integrated Project on Aerosol Cloud Climate Interactions (EUCAARI) $^{76}$. At Manaus, we restrict our comparisons to the wet season (Jan-Jun) since particle mass and number concentrations in the dry season are dominated by transported regional biomass burning aerosol ${ }^{75}$.

Calculation of radiative effects. We use the Suite Of Community RAdiative Transfer codes based on Edwards and Slingo ${ }^{77}$ (SOCRATES) to evaluate the radiative impact of deforestation induced changes to atmospheric composition and the land-surface. We operate SOCRATES with nine bands in the longwave (LW) and six bands in the shortwave (SW). We take monthly mean temperature and water vapour concentrations from ECMWF re-analysis data and use cloud fields for the year 2000 from the ISCCP-D2 archive ${ }^{51}$. Taking this approach, we have previously demonstrated that the sensitivity of direct and indirect aerosol radiative effects to using either a single year or a multi-annual mean cloud climatology is small $^{19}$.

Aerosol radiative effects. We use SOCRATES to calculate aerosol radiative effects by evaluating the difference in net ( $\mathrm{SW}+\mathrm{LW}$ ) top-of-atmosphere all-sky radiative flux between each of our deforestation experiments and the control simulation. We compute the aerosol optical properties (scattering and absorption coefficients and the asymmetry parameter) for each size mode and spectral band in order to determine the direct radiative forcing (DRF) for each deforestation experiment ${ }^{78}$. The first indirect radiative forcing (IRF), or cloud albedo effect, is determined from the change to cloud droplet number concentration (CDNC) associated with each deforestation experiment. This approach has been described in previous studies ${ }^{19,20}$

We use the monthly mean aerosol size distribution and the hygroscopicity parameter $(\kappa)$ approach $^{79}$ to calculate cloud droplet number concentrations ${ }^{80}$, assuming a uniform updraught velocity of $0.3 \mathrm{~m} \mathrm{~s}^{-1}$ over land and $0.15 \mathrm{~m} \mathrm{~s}^{-1}$ over sea. We assign the following $\kappa$ values to our simulated aerosol components: sulphate (0.61, assuming ammonium sulphate), black carbon (0.0), sea-salt (1.28), and particulate organic matter $(0.1)$. While there is considerable uncertainty associated with the hygroscopicity of organic material observed in the atmosphere, $\kappa$ values close to 0.1 have frequently been reported for secondary organic aerosol produced from BVOC oxidation ${ }^{81,82}$. A multi-component $\kappa$ is obtained by volume weighting the $\kappa$ values of each component.

We assume a uniform control cloud droplet effective radius $\left(r_{\mathrm{e} 1}\right)$ of $10 \mu \mathrm{m}$ to maintain consistency with the ISCCP derivation of liquid water path. For each deforestation experiment an effective radius $\left(r_{\mathrm{e} 2}\right)$ is calculated using monthly mean cloud droplet number fields $\mathrm{CDNC}_{1}$ and $\mathrm{CDNC}_{2}$ (as in Eq. 2, where $\mathrm{CDNC}_{1}$ represents the control simulation, and $\mathrm{CDNC}_{2}$ represents the deforested scenario).

$$
r_{\mathrm{e} 2}=r_{\mathrm{e} 1} \times\left[\frac{\mathrm{CDNC}_{1}}{\mathrm{CDNC}_{2}}\right]^{\frac{1}{3}}
$$

The first IRF due to deforestation is then calculated by comparing the net topof-atmosphere all-sky radiative fluxes obtained using the varying $r_{\mathrm{e} 2}$ values, to those of the control simulation with fixed $r_{\mathrm{e} 1}$. We do not calculate the second aerosol indirect, or cloud lifetime, effect in these offline experiments.

$\mathbf{O}_{\mathbf{3}}$ and $\mathbf{C H}_{\mathbf{4}}$ radiative effects. To calculate the radiative forcing associated with deforestation-induced changes to tropospheric $\mathrm{O}_{3}$ concentrations, we use the radiative kernel approach developed by ref. ${ }^{30}$. $\mathrm{O}_{3}$ radiative effects calculated using the kernel approach agree well with those calculated using the SOCRATES radiative transfer model, both when $\mathrm{O}_{3}$ concentrations retrieved from Tropospheric Emission Spectrometer (TES) satellite measurements are used and when $\mathrm{O}_{3}$ concentrations are taken from the TOMCAT model ${ }^{30}$. Deforestation-induced changes to $\mathrm{O}_{3}$ concentration will alter the production of the hydroxyl radical $(\mathrm{OH})$, and therefore $\mathrm{CH}_{4}$ concentrations. In turn, this will affect peroxy radical production and feedback on to $\mathrm{O}_{3}$ concentrations. The change in $\mathrm{O}_{3}$ concentration associated with this primary mode of tropospheric photochemistry is calculated following ref. ${ }^{83}$; we then apply a value of $0.032 \mathrm{~W} \mathrm{~m}^{-2} \mathrm{DU}^{-1}$ (following ref. ${ }^{24}$ ) to diagnose a RF. We add this primary mode response to the RF calculated directly from $\mathrm{O}_{3}$ changes using the radiative kernel.

Our 1-year TOMCAT simulations do not allow for a direct calculation of the impact of a changing source of BVOCs on $\mathrm{CH}_{4}$ concentrations, owing its long atmospheric lifetime (approximately 10 years). As such, we use the concentration of $\mathrm{OH}$ as a proxy to infer changes to $\mathrm{CH}_{4}$ lifetime, and therefore concentration. The change in global annual tropospheric mean $\left(\mathrm{CH}_{4}\right.$ reaction weighted, using a climatological tropopause) ${ }^{84} \mathrm{OH}$ concentration is used to estimate the change to tropospheric chemical $\mathrm{CH}_{4}$ lifetime, and hence steady-state $\mathrm{CH}_{4}$ concentration $^{85,86}$, assuming a feedback factor of $1.4\left(\right.$ ref. $^{87)}$. The change in steadystate $\mathrm{CH}_{4}$ concentration is then used to quantify the global annual mean radiative forcing 88 associated with each deforestation scenario, assuming a present-day $\mathrm{N}_{2} \mathrm{O}$ concentration of $324.2 \mathrm{ppb}$ (ref. $^{35)}$.

Calculation of $\mathrm{CO}_{2}$ and surface albedo radiative effects. To understand the importance of the radiative forcings we calculate from changes in SLCFs, we also estimate the radiative impacts of altered atmospheric $\mathrm{CO}_{2}$ and surface albedo associated with our deforestation scenarios.

Changes to atmospheric $\mathrm{CO}_{2}$ concentration, for 100 years after deforestation were taken from ref. ${ }^{9}$, in which the Lawrence Livermore National Laboratory INCCA (Integrated Climate and Carbon) model was used to assess various impacts of simulated global and regional (using the same latitude bands as this study) forest removal in the year 2000. When forests are replaced by grass in these simulations, the carbon they stored is gradually added to the litter pool. The simulations proceed for 100 years following deforestation, allowing the carbon released (a total of $818 \operatorname{Pg}(\mathrm{C})$ over 100 years) to partition amongst the atmosphere, ocean and land carbon sinks. Anthropogenic $\mathrm{CO}_{2}$ emissions follow the SRES A2 scenario ${ }^{89}$ from 2000 to 2100. The radiative forcing due to a change in $\mathrm{CO}_{2}$ concentration is calculated as in Eq. 2 following ref. ${ }^{88}$, where $C_{\text {def }}$ represents the atmospheric $\mathrm{CO}_{2}$ concentration (in ppmv) in the deforestation scenario, and $C_{\text {con }}$ that in the control scenario.

$$
\mathrm{RF}_{\mathrm{CO}_{2}}=5.35 \ln \frac{C_{\mathrm{def}}}{C_{\mathrm{con}}}
$$

The ratio of SW radiation incident upon and reflected by the surface, for each grid cell in the CLM, was used to determine the SW surface albedo for each deforestation scenario. In the CLM, LAIs are adjusted for burial by snow, according to snow depth and vegetation height, which in turn affects the amount of SW radiation reflected by the surface. The radiative transfer model was then used to evaluate the radiative impact of the change in albedo between the various scenarios by comparing the net top-of-atmosphere flux.

We note that taking $\mathrm{CO}_{2}$ concentrations from ref. ${ }^{9}$ means that the simulated changes to the land surface may have been slightly different (in terms of plant functional type distribution, assumed leaf area indices and stored biomass) to those assumed in the CLM experiments used to determine the RFs due to SLCFs and albedo. Additionally, since present-day gas-phase and aerosol emissions, and concentrations are assumed when calculating the RFs associated with changes to SLCFs, we note that these values would alter if calculated assuming emissions and concentrations representative of a future period.

Calculation of global temperature potentials. To estimate the surface temperature change, the RF scenarios are incorporated into a simple two-layer energy balance model used in the Global Temperature Potential (GTP) derivation ${ }^{90}$, choosing an equilibrium climate sensitivity of $3 \mathrm{~K}$; the mid-range value from the latest IPCC assessment report. As climate sensitivity is uncertain, the temperature changes computed here are illustrative.

Data availability. The data sets generated, and analysed, during the current study are available from the corresponding author upon request.

Received: 27 July 2016 Accepted: 29 November 2017

Published online: 11 January 2018

\section{References}

1. Ramankutty, N. \& Foley, J. A. Estimating historical changes in global land cover: croplands from 1700 to 1992. Glob. Biogeochem. Cycles 13, 997-1027 (1999). 
2. Hansen, M. C. et al. High-resolution global maps of 21st-century forest cover change. Science 342, 850-853 (2013).

3. Davidson, E. A. et al. The Amazon basin in transition. Nature 481, 321-328 (2012).

4. Gaveau, D. L. A. et al. Four decades of forest persistence, clearance and logging on Borneo. PLoS ONE 9, e101654 (2014).

5. Griscom, B. W. et al. Natural climate solutions. Proc. Natl Acad. Sci. 114, 11645-11650 (2017).

6. Anderson, R. G. et al. Biophysical considerations in forestry for climate protection. Front Ecol. Environ. 9, 174-182 (2011).

7. Lawrence, P. J. et al. Simulating the Biogeochemical and biogeophysical impacts of transient land cover change and wood harvest in the community climate system model (CCSM4) from 1850 to 2100. J. Clim. 25, 3071-3095 (2012).

8. Betts, R. A. Offset of the potential carbon sink from boreal forestation by decreases in surface albedo. Nature 408, 187-190 (2000).

9. Bala, G. et al. Combined climate and carbon-cycle effects of large-scale deforestation. PNAS 104, 6550-6555 (2007).

10. Davin, E. L. \& de Noblet-Ducoudre, N. Climatic impact of global-scale deforestation: radiative versus nonradiative processes. J. Clim. 23, 97-112 (2010).

11. Bonan, G. B. Forests and climate change: forcings, feedbacks, and the climate benefits of forests. Science 320, 1444-1449 (2008).

12. van der Werf, G. R. et al. $\mathrm{CO}_{2}$ emissions from forest loss. Nat. Geosci. 2 737-738 (2009)

13. Li, Y. et al. Local cooling and warming effects of forests based on satellite observations. Nat. Commun. 6, 6603 (2015).

14. Monks, P. S. et al. Tropospheric ozone and its precursors from the urban to the global scale from air quality to short-lived climate forcer. Atmos. Chem. Phys. 15, 8889-8973 (2015).

15. Metzger, A. et al. Evidence for the role of organics in aerosol particle formation under atmospheric conditions. Proc. Natl Acad. Sci. 107, 6646-6651 (2010).

16. Kirkby, J. et al. Ion-induced nucleation of pure biogenic particles. Nature 533, 521-526 (2016).

17. Riipinen, I. et al. Organic condensation: a vital link connecting aerosol formation to cloud condensation nuclei (CCN) concentrations. Atmos. Chem. Phys. 11, 3865-3878 (2011).

18. Tröstl, J. et al. The role of low-volatility organic compounds in initial particle growth in the atmosphere. Nature 533, 527-531 (2016).

19. Rap, A. et al. Natural aerosol direct and indirect radiative effects. Geophys. Res. Lett. 40, 3297-3301 (2013).

20. Scott, C. E. et al. The direct and indirect radiative effects of biogenic secondary organic aerosol. Atmos. Chem. Phys. 14, 447-470 (2014).

21. Spracklen, D. V., Bonn, B. \& Carslaw, K. S. Boreal forests, aerosols and the impacts on clouds and climate. Philos. Trans. R. Soc. A 366, 4613-4626 (2008).

22. Unger, N. Human land-use-driven reduction of forest volatiles cools global climate. Nat. Clim. Change 4, 907-910 (2014).

23. D'Andrea, S. D. et al. Aerosol size distribution and radiative forcing response to anthropogenically driven historical changes in biogenic secondary organic aerosol formation. Atmos. Chem. Phys. 15, 2247-2268 (2015).

24. Ward, D. S., Mahowald, N. M. \& Kloster, S. Potential climate forcing of land use and land cover change. Atmos. Chem. Phys. 14, 12701-12724 (2014).

25. Scott, C. E. et al. Impact on short-lived climate forcers (SLCFs) from a realistic land-use change scenario via changes in biogenic emissions. Faraday Discuss. 200, 101-120 (2017)

26. Ward, D. S. \& Mahowald, N. M. Local sources of global climate forcing from different categories of land use activities. Earth Syst. Dynam 6, 175-194 (2015).

27. Hamilton, D. S. et al. Occurrence of pristine aerosol environments on a polluted planet. Proc. Natl Acad. Sci. 111, 18466-18471 (2014).

28. Spracklen, D. V. et al. Aerosol mass spectrometer constraint on the global secondary organic aerosol budget. Atmos. Chem. Phys. 11, 12109-12136 (2011).

29. Lee, L. A. et al. The magnitude and causes of uncertainty in global model simulations of cloud condensation nuclei. Atmos. Chem. Phys. 13, 8879-8914 (2013).

30. Rap, A. et al. Satellite constraint on the tropospheric ozone radiative effect. Geophys. Res. Lett. 42, 5074-5081 (2015).

31 . Unger N. On the role of plant volatiles in anthropogenic global climate change. Geophys. Res. Lett. 41, 8563-8569 (2014).

32. Taraborrelli, D. et al. Hydroxyl radical buffered by isoprene oxidation over tropical forests. Nat. Geosci. 5, 190-193 (2012).

33. Fuchs, H. et al. Experimental evidence for efficient hydroxyl radical regeneration in isoprene oxidation. Nat. Geosci. 6, 1023-1026 (2013).

34. Snyder, P. K., Delire, C. \& Foley, J. A. Evaluating the influence of different vegetation biomes on the global climate. Clim. Dyn. 23, 279-302 (2004).

35. Myhre G., et al. in: Climate Change 2013: The Physical Science Basis. Contribution of Working Group I to the Fifth Assessment Report of the Intergovernmental Panel on Climate Change (eds Stocker, T. F., et al.). (Cambridge University Press, New York, USA, 2013).
36. Jones, A. D., Collins, W. D. \& Torn, M. S. On the additivity of radiative forcing between land-use change and greenhouse gases. Geophys. Res. Lett. 40, 4036-4041 (2013).

37. Forster, P. M. et al. Evaluating adjusted forcing and model spread for historical and future scenarios in the CMIP5 generation of climate models. J. Geophys. Res.: Atmospheres 118, 1139-1150 (2013).

38. Guenther, A. B. et al. The Model of Emissions of Gases and Aerosols from Nature version 2.1 (MEGAN2.1): an extended and updated framework for modeling biogenic emissions. Geosci. Model Dev. 5, 1471-1492 (2012).

39. Jardine, K. et al. Within-canopy sesquiterpene ozonolysis in Amazonia. J. Geophys. Res. 116, D19301 (2011).

40. Hallquist, M. et al. The formation, properties and impact of secondary organic aerosol: current and emerging issues. Atmos. Chem. Phys. 9, 5155-5236 (2009).

41. Hoyle, C. R. et al. A review of the anthropogenic influence on biogenic secondary organic aerosol. Atmos. Chem. Phys. 11, 321-343 (2011).

42. Agrawal, A., Nepstad, D. \& Chhatre, A. Reducing emissions from deforestation and forest degradation. Annu. Rev. Environ. Resour. 36, 373-396 (2011).

43. Alkama, R. \& Cescatti, A. Biophysical climate impacts of recent changes in global forest cover. Science 351, 600-604 (2016).

44. Lawrence, D. M. et al. Parameterization improvements and functional and structural advances in Version 4 of the Community Land Model. J. Adv. Model. Earth Syst. 3, M03001 (2011)

45. Qian, T., Dai, A., Trenberth, K. E. \& Oleson, K. W. Simulation of global land surface conditions from 1948 to 2004. part i: forcing data and evaluations. J. Hydrometeorol. 7, 953-975 (2006).

46. Lawrence, P. J. \& Chase, T. N. Representing a new MODIS consistent land surface in the Community Land Model (CLM 3.0). J. Geophys. Res.: Biogeosciences 112, G01023 (2007).

47. Hansen, M. C. et al. Global percent tree cover at a spatial resolution of 500 meters: first results of the MODIS vegetation continuous fields algorithm. Earth Interact. 7, 1-15 (2003).

48. Hurtt, G. C. et al. Harmonization of land-use scenarios for the period 1500-2100: 600 years of global gridded annual land-use transitions, wood harvest, and resulting secondary lands. Clim. Change 109, 117 (2011).

49. Chipperfield, M. P. New version of the TOMCAT/SLIMCAT off-line chemical transport model: Intercomparison of stratospheric tracer experiments. Q. J. $R$. Meteorol. Soc. 132, 1179-1203 (2006).

50. Mann, G. W. et al. Description and evaluation of GLOMAP-mode: a modal global aerosol microphysics model for the UKCA composition-climate model. Geosci. Model Dev. 3, 519-551 (2010).

51. Rossow, W. B. \& Schiffer, R. A. Advances in Understanding Clouds from ISCCP. B Am. Meteorol. Soc. 80, 2261-2287 (1999).

52. Bond, T. C. et al. A technology-based global inventory of black and organic carbon emissions from combustion. J. Geophys. Res. 109, D14203 (2004).

53. Cofala J., Amann M., Klimont Z. S., Schopp W. in: Internal Report of the Transboundary Air Pollution Programme (International Institute for Applied Systems Analysis, Laxenburg, 2005).

54. van der Werf, G. R. et al. Global fire emissions and the contribution of deforestation, savanna, forest, agricultural, and peat fires (1997-2009). Atmos. Chem. Phys. 10, 11707-11735 (2010)

55. Kettle, A. J. \& Andreae, M. O. Flux of dimethylsulfide from the oceans: A comparison of updated data sets and flux models. J. Geophys. Res.: Atmospheres 105, 26793-26808 (2000).

56. Nightingale, P. D. et al. In situ evaluation of air-sea gas exchange parameterizations using novel conservative and volatile tracers. Glob. Biogeochem. Cycles 14, 373-387 (2000).

57. Andres, R. J. \& Kasgnoc, A. D. A time-averaged inventory of subaerial volcanic sulfur emissions. J. Geophys. Res. 103, 25251-25261 (1998).

58. Halmer, M. M., Schmincke, H. U. \& Graf, H. F. The annual volcanic gas input into the atmosphere, in particular into the stratosphere: a global data set for the past 100 years. J. Volcanol. Geotherm. Res. 115, 511-528 (2002).

59. Fuchs, N. A., Sutugin, A. G. in: Topics in Current Aerosol Research (eds Hidy, G. M. \& Brock, J. R.) (Pergamon, New York, USA, 1971).

60. Kulmala, M. et al. On the formation, growth and composition of nucleation mode particles. Tellus B 53, 479-490 (2001).

61. Monks, S. A. et al. The TOMCAT global chemical transport modelv1.6: description of chemical mechanism and model evaluation. Geosci. Model Dev. 10, 3025-3057 (2017).

62. Kinnison, D. E. et al. Sensitivity of chemical tracers to meteorological parameters in the MOZART-3 chemical transport model. J. Geophys. Res.: Atmospheres 112, D20302 (2007).

63. Emmons, L. K. et al. Description and evaluation of the model for ozone and related chemical tracers, version 4 (MOZART-4). Geosci. Model Dev. 3, 43-67 (2010).

64. Poschl, U., von Kuhlmann, R., Poisson, N. \& Crutzen, P. J. Development and intercomparison of condensed isoprene oxidation mechanisms for global atmospheric modeling. J. Atmos. Chem. 37, 29-52 (2000). 
65. Lamarque, J. F. et al. Historical (1850-2000) gridded anthropogenic and biomass burning emissions of reactive gases and aerosols: methodology and application. Atmos. Chem. Phys. 10, 7017-7039 (2010).

66. Granier, C. et al. POET, a database of surface emissions of ozone precursors Available at: http://www.aero.jussieu.fr/projet/ACCENT/POET.php (2005).

67. Olivier, J. G. J., Berdowski, J. J. M. in: The Climate System (eds Berdowski, J., Guicherit, R. \& Heij, B. J.) (A.A. Balkema Publishers/Swets \& Zeitlinger Publishers, Lisse, The Netherlands, 2001).

68. Bloom, A. A., Palmer, P. I., Fraser, A. \& Reay, D. S. Seasonal variability of tropical wetland $\mathrm{CH}_{4}$ emissions: the role of the methanogen-available carbon pool. Biogeosciences 9, 2821-2830 (2012).

69. Patra, P. K. et al. TransCom model simulations of $\mathrm{CH}_{4}$ and related species: linking transport, surface flux and chemical loss with $\mathrm{CH}_{4}$ variability in the troposphere and lower stratosphere. Atmos. Chem. Phys. 11, 12813-12837 (2011).

70. Zhang, L., Gong, S., Padro, J. \& Barrie, L. A size-segregated particle dry deposition scheme for an atmospheric aerosol module. Atmos. Environ. 35, 549-560 (2001)

71. Aalto, P. et al. Physical characterization of aerosol particles during nucleation events. Tellus B 53, 344-358 (2001).

72. Ng, N. L. et al. An aerosol chemical speciation monitor (ACSM) for routine monitoring of the composition and mass concentrations of ambient aerosol. Aerosol Sci. Technol. 45, 780-794 (2011).

73. Hari, P. \& Kulmala, M. Station for measuring ecosystem-atmosphere relations (SMEAR II). Boreal Environ. Res. 10, 315-322 (2005).

74. Martin, S. T. et al. An overview of the amazonian aerosol characterization experiment 2008 (AMAZE-08). Atmos. Chem. Phys. 10, 11415-11438 (2010).

75. Rizzo, L. V. et al. Long term measurements of aerosol optical properties at a primary forest site in Amazonia. Atmos. Chem. Phys. 13, 2391-2413 (2013).

76. Gilardoni, S. et al. Sources of carbonaceous aerosol in the Amazon basin. Atmos. Chem. Phys. 11, 2747-2764 (2011).

77. Edwards, J. M. \& Slingo, A. Studies with a flexible new radiation code. I: Choosing a configuration for a large-scale model. Q. J. R. Meteorol. Soc. 122, 689-719 (1996).

78. Bellouin, N. et al. Impact of the modal aerosol scheme GLOMAP-mode on aerosol forcing in the Hadley Centre Global Environmental Model. Atmos. Chem. Phys. 13, 3027-3044 (2013).

79. Petters, M. D. \& Kreidenweis, S. M. A single parameter representation of hygroscopic growth and cloud condensation nucleus activity. Atmos. Chem. Phys. 7, 1961-1971 (2007).

80. Fountoukis, C. \& Nenes, A. Continued development of a cloud droplet formation parameterization for global climate models. J. Geophys. Res. 110, D11212 (2005).

81. Engelhart, G. J., Moore, R. H., Nenes, A. \& Pandis, S. N. Cloud condensation nuclei activity of isoprene secondary organic aerosol. J. Geophys. Res. 116, D02207 (2011).

82. Dusek, U. et al. Enhanced organic mass fraction and decreased hygroscopicity of cloud condensation nuclei (CCN) during new particle formation events. Geophys. Res. Lett. 37, L03804 (2010).

83. Naik, V. et al. Net radiative forcing due to changes in regional emissions of tropospheric ozone precursors. J. Geophys. Res.: Atmospheres 110, D24 (2005).

84. Lawrence, M. G., Jöckel, P. \& von Kuhlmann, R. What does the global mean $\mathrm{OH}$ concentration tell us? Atmos. Chem. Phys. 1, 37-49 (2001).

85. Fuglestvedt, J. S. et al. Climatic forcing of nitrogen oxides through changes in tropospheric ozone and methane; global 3D model studies. Atmos. Environ. 33, 961-977 (1999)

86. Berntsen, T. K. et al. Response of climate to regional emissions of ozone precursors: sensitivities and warming potentials. Tellus B 57, 283-304 (2005).

87. Ehhalt, D., et al. in: Climate Change 2001: The Physical Science Basis. Contribution of Working Group I to the Third Assessment Report of the Intergovernmental Panel on Climate Change (eds Houghton, J. T. et al.) (Cambridge University Press, 2001)
88. Myhre, G., Highwood, E. J., Shine, K. P., \& Stordal, F. New estimates of radiative forcing due to well mixed greenhouse gases. Geophys. Res. Lett. 25, 2715-2718 (1998).

89. Nakicenovic, N. et al. Special Report on Emission Scenarios. (eds Nakicenovic, N. \& Swart, R.) (Cambridge University Press, 2000).

90. Shine, K. P., Fuglestvedt, J. S., Hailemariam, K. \& Stuber, N. Alternatives to the global warming potential for comparing climate impacts of emissions of greenhouse gases. Clim. Change 68, 281-302 (2005).

\section{Acknowledgements}

We acknowledge support from NERC (NE/H524673/1, NE/J004723/1, NE/G015015/1, NE/K015966/1), EU Horizon 2020 (grant agreement numbers 641816 and 654109), EPSRC (EP/I014721/1), ERC (227463-ATMNUCLE) and the United Bank of Carbon (UBoC). This work used ARC1 and ARC2, part of the High Performance Computing Facilities at the University of Leeds, UK, as well as the ARCHER UK National Supercomputing Service. Aerosol measurements at Hyytiälä were supported by the Academy of Finland Centre of Excellence (1118615 \& 1127372), and the Cryosphere-Atmosphere Interactions in a Changing Arctic Climate (CRAICC) programme. Aerosol measurements in the Amazon were supported by Fundacao de Amparo a Pesquisa do Estado de Sao Paulo (FAPESP-AEROCLIMA 08/58100-2), Conselho Nacional de Desenvolvimento Cientıfico $(\mathrm{CNPq})$ and European Integrated FP6 project on Aerosol Cloud Climate and Air Quality Interactions (EUCAARI-34684, 036833-2), under the scope of LBA experiment; we thank INPA (Instituto Nacional de Pesquisas da Amazonia) for the coordination work of the LBA Experiment.

\section{Author contributions}

C.E.S., D.V.S., P.M.F. and K.S.C. designed the experiments. C.E.S., S.A.M. and S.R.A performed the model simulations. A.R., M.P.C., C.L.R., and C.W. provided data for model simulations and subsequent calculations. C.E.S., D.V.S., S.A.M. and P.M.F. performed the analysis. M.A., P.A., M.E., S.G., L.H., M.K., T.P., L.R., E.S. and E.V. provided atmospheric measurement data. All authors contributed to scientific discussion and helped write the manuscript.

\section{Additional information}

Supplementary Information accompanies this paper at https://doi.org/10.1038/s41467 017-02412-4.

Competing interests: The authors declare no competing financial interests.

Reprints and permission information is available online at http://npg.nature.com/ reprintsandpermissions/

Publisher's note: Springer Nature remains neutral with regard to jurisdictional claims in published maps and institutional affiliations.

Open Access This article is licensed under a Creative Commons Attribution 4.0 International License, which permits use, sharing, adaptation, distribution and reproduction in any medium or format, as long as you give appropriate credit to the original author(s) and the source, provide a link to the Creative Commons license, and indicate if changes were made. The images or other third party material in this article are included in the article's Creative Commons license, unless indicated otherwise in a credit line to the material. If material is not included in the article's Creative Commons license and your intended use is not permitted by statutory regulation or exceeds the permitted use, you will need to obtain permission directly from the copyright holder. To view a copy of this license, visit http://creativecommons.org/ licenses/by/4.0/.

(C) The Author(s) 2018 